\title{
Comparison of active transcription regions of lampbrush chromosomes with the mitotic chromosome G pattern in the European domestic goose Anser anser
}

\author{
Katarzyna Andraszek and Elżbieta Smalec
}

Department of Animal Genetics and Horse Breeding, Institute of Bioengineering and Animal Breeding, University of Life Sciences and Humanities, Poland

\begin{abstract}
The most complete information on the karyotype is acquired through the observation of chromosomes obtained from dividing cells. A high number of chromosomes and the presence of microchromosomes in the bird karyotype have made cytogeneticists look for other sources of information on chromosomes. Information sources of great value for the bird karyotype analysis are meiotic chromosomes, specifically represented by lampbrush chromosomes. Lampbrush chromosomes (LBCs) found in developing oocytes of birds are perceived as a new model in cytogenetics which is especially important in the analysis of bird chromosomes. A typical LBC analysis enables one to assess transcription activity on the basis of LBC morphology (inactive chromomeres and side loops). A comparison of lampbrush chromosome transcription activity and the GTG pattern of the corresponding mitotic chromosomes have proven that active transcription regions with side loops correspond to G-positive bands on mitotic chromosomes.
\end{abstract}

Keywords: geese, Anser anser, lampbrush chromosomes (LBCs), mitotic chromosomes, transcription, G-bands

\section{Zusammenfassung}

\section{Vergleich zwischen den transkriptionell aktiven Regionen der Lampenbürstenchromosomen und dem G-Muster der mitotischen Chromosomen der Europäischen Hausgans Anser anser}

Die vollständigsten Informationen über den Karyotyp erhält man durch die Beobachtung von Chromosomen sich teilendender Zellen. Die große Anzahl von Chromosomen und das Vorhandensein von Mikrochromosomen im Vogelkaryotyp haben Zytogenetiker zum Suchen von anderen Informationsquellen über Chromosomen veranlasst. Eine wertvolle Informationsquelle für die Erforschung des Vogelkaryotyps sind meiotische Chromosomen - insbesondere die Lampenbürstenchromosomen, die in sich entwickelnden Oozyten der Vögel zu finden sind.

Siewerden als ein neues Modell in der Zytogenetikwahrgenommen, das einewesentliche Rolle bei der Chromosomenanalyse der Vögel spielt. Die Analyse der Lampenbürstenchromosomen ermöglicht eine Beurteilung der transkriptionellen Aktivität auf Grund der Morphologie 
dieser Chromosomen (inaktive Chromomeren und seitliche Schleifen). Der Vergleich zwischen der transkriptionellen Aktivität von Lampenbürstenchromosomen und dem GTGMuster der entsprechenden mitotischen Chromosomen bestätigte, dass transkriptionell aktive Regionen mit seitlichen Schleifen den positiven G-Streifen auf den mitotischen Chromosomen entsprechen.

Schlüsselwörter: Hausgans Anser anser, mitotische Chromosomen, Transkription, G-Streifen

\section{Introduction}

Karyotypes of most modern birds include 5 or 6 pairs of macrochromosomes and between 32 and 36 pairs of microchromosomes (Christidis 1990, Mizuno \& Macgregor 1998). The length of metaphase microchromosomes does not exceed 2 micrometres and the standard staining techniques do not enable the identification of bird microchromosomes even in relation to the centromere position (Bitgood \& Shoffner 1990). The only standardized bird chromosome description is the karyotype of Gallus domesticus that comprises the first eight pairs of autosomes and the ZW chromosomes. It serves as a benchmark for the research on other bird species (Ladjali-Mohammedi et al. 1999, Schmid et al. 2000, 2005, Guttenbach et al. 2003).

Thefew analyses of chromosomes of the genus Anser primarily concerned the determination of chromosome diploid number and morphology, and only sporadically the structure. The karyotype standard for Anseriformes is still unavailable. Morphological chromosome structure, with particular emphasis on the differences in the fourth chromosome pair set-up in various goose species, was analysed by: Bhatnagar (1968), Itoh et al. (1969), Shoffner et al. (1979), Silversides et al. (1988), Hidas (1993), Rabsztyn et al. (1998) and Jaszczak et al. (1999, 2002). Chromatin structure was investigated by Mayr et al. (1990) and Apitz et al. (1995). The only detailed reports on replication patterns of goose chromosomes are the papers by Andraszek \& Smalec (2007) on particular $\mathrm{G}$ band identification in the first eight macrochromosomes and the sex chromosomes of the goose (Anser anser) and by Wójcik \& Smalec $(2007,2008)$ on the RGB pattern profile of goose (Anser anser and Anser cygnoides) chromosomes.

In the case of bird karyotypes, meiotic chromosomes, specifically represented by lampbrush chromosomes, are an invaluable source of information. Lampbrush chromosomes are greatly elongated diplotene bivalents found in the growing oocytes of all animals except mammals, some insects and some reptiles. The lampbrush form of even the smallest of the chromosomes is easily visible and shows useful linear differentiation. In Gallus domesticus they can be as much as 30 times larger than their mitotic equivalents (Kropotova \& Gaginskaya 1984, Macgregor \& Varley 1988, Galkina et al. 2006, Gaginskaya et al. 2009). The axis of every LBC consists of two sister chromatids. The chromatin in homologous parts of a bivalent is condensed (chromomeres) or it can be decondensed forming side loops, two for each chromosome and four at the bivalent level. A set of LBCs in an oocyte may include a few thousand loops according to the species or even the individual. Each loop corresponds to the specific DNA sequence which, at the tetrad level, has three copies (Vlad \& Macgregor 1975, Macgregor 1987, Morgan 2002, 2007, Austin et al. 2009). 
Lampbrush chromosomes constitute a model in research on transcription regulation because the LBC transcription activity can be seen under the light microscope and observed as changes in their morphology (Morgan 2002). Transcription activity analysis is based on the assumption that transcription takes place in LBC side loops. Decreased transcription activity is reflected in side loops becoming smaller and smaller (Gall 1983, Callan et al. 1987, Gaginskaya \& Tsvetkov 1988, Morgan 2002, 2007, Galkina et al. 2006, Gaginskaya et al. 2009). In turn, a routine mitotic chromosome analysis makes it possible to describe only the chromosome morphology. Transcription activity can be assessed only by molecular methods which are designed to detect the amount of transcription products.

As a tool, lampbrush chromosomes were introduced into poultry cytogenetics by Kropotova \& Gaginskaya (1984), and by Hutchison (1987). The former authors support a thesis that chromosomes provide valuable information on bird gene expression and are irreplaceable in cytogenetic research on animals with small genomes in which a large number of smallsized mitotic chromosomes makes it impossible for scientists to carry out microchromosome analysis. As in the case of banded patterns of mitotic chromosomes, LBCs are characterised by a special arrangement of active and inactive chromomeres visible as a pattern of side loops and regions without loops. In the second report on chicken genes and chromosomes, LBCs were recognized as a new model in avian cytogenetics (Schmid et al. 2005).

Lampbrush chromosomes found in various species are characterised by a very similar structure and perform the same function. Structural similarity of LBCs is especially distinct in birds (Saifitdinova 2003, Krasikova et al. 2004, Galkina et al. 2006). Bird LBCs are characterised by a similar location of chiasmas and marker loops, and they differ only in size, which is due to a different size of genomes of particular species (Angelier et al. 1984, 1990, Morgan 2002, 2007, Rodionov \& Chechik 2002). As in the case of mitotic chromosomes, also lampbrush chromosomes of Gallus domesticus are readily examined and constitute a reference point in studies on LBCs in other bird species (Schmid et al. 2005).

Macgregor (1984) and Hutchison (1987) were the first to profile lampbrush chromosome structure. They were also the first to confirm the fact of loop transcription. Rodionov et al. (1989) analysed lampbrush chromosomes of Gallus domesticus and Coturnix japonica, using fluorochrome staining. In their research they identified three types of marker loops and performed a comparative analysis of the mitotic and lampbrush chromosome patterns obtained by chromomycin A3/distamycin (CMA/DA) staining. A detailed analysis of the first five lampbrush bivalents and sex bivalent was performed by Chelysheva et al. (1990). Rodionov (1996), Rodionov et al (2002a, 2002b) and Rodionov \& Chechik (2002) analysed the lay-out and number of chiasms in lampbrush chromosomes of Gallus domesticus and investigated marker loops in Gallus gallus, Coturnix japonica, Columba palumbus and Fringilla coelebs. Solovei et al. $(1992,1993,1994,1996)$ described the positions of the loops, chromomeres and transcription units at the ends of LBCs in four bird species. They concluded that the configuration is different than that of amphibians. Solovei et al. (1995) found that in Gallus domesticus oocytes, the K/J proteins or their analogues, those known to participate in mRNA formation in man, are closely connected with the C-rich RNA transcripts that form on lampbrush chromosome loops. A profile of the first five macrobivalents and sex bivalent of Gallus domesticus and Coturnix japonica was published in the Second Report on Chicken Genes and Chromosomes (Schmid et al. 2005) 
The purpose of the paper was to compare transcription-active regions of lampbrush chromosomes with the GTG pattern of corresponding mitotic chromosomes of the European domestic goose Anser anser.

\section{Material and methods}

The research was carried out on the lampbrush chromosomes and mitotic chromosomes of the European domestic goose Anser anser.

\section{Isolation of lampbrush chromosomes}

Chromosomes in the form of lampbrushes were prepared by manual isolation from oocytes with diameters of $1.5-3.5 \mathrm{~mm}$ obtained from sexually mature goose using the standard procedure (Macgregor \& Varley 1988) modified for bird oocytes (Solovei et al. 1992, Rodionov \& Chechik 2002). The preparations were stained with Coomassie Blue R250. The first five macrobivalents and lampbrush sex bivalents (sex LBCs) were identified on the basis of their length and marker structure, using the cytological map of Gallus domesticus LBCs described by Chelysheva et al. (1990), Rodionov et al. (2002a) and Schmid et al. (2005).

\section{Izolation of mitotic chromosomes}

The mitotic chromosomes were isolated from peripheral blood lymphocytes applying standard procedures. The pattern of $\mathrm{G}$ bands was determined by means of a relevant technique (Seabright 1971) modified for Anser anser by Apitz et al. (1995). The pattern of $\mathrm{G}$ bands was determined on the basis of an analysis of 688 chromosomes obtained from 132 metaphase plates. The description of chromosome morphology and classification was performed following Fechheimer (1990). The $p$ arms of the chromosomes of pair 1 and 2 and the $q$ arms of the chromosomes of pair 1, 2, 3, and 4 as well as sex chromosome $Z$ were divided into regions according to the standard of $\mathrm{G}$ band identification on the chromosomes of Gallus domesticus (Ladjali-Mohammedi et al. 1999)

The preparations obtained were analysed under the Olympus BX 50 light microscope. A detailed computer analysis was carried out using the Multiscan image analysing system, the Karyotype software, and graphic software compatible with the system.

\section{Comparison of transcription activity on the LBCs and the GTG pattern}

The first five lampbrush macrobivalents and lampbrush sex bivalents were subjected to comparative analysis. For each bivalent a graphic arrangement of loop regions and active transcription regions, and those without loops which are transcription-inactive, was prepared. The term »band « was applied to the mitotic chromosomes only, whereas in the case of the lampbrush chromosomes the regions of transcription-active chromatin were called »blocks". In the Results section, the blocks of transcription-active chromatin were marked with consecutive capital letters of the alphabet according to the standard (Schmid et al. 2005).

The obtained pattern of blocks was compared with the arrangement of GTG bands on the corresponding mitotic chromosomes following similar studies in chicken and quail (Galkina et al. 2001, Rodionov et al. 2002a, Schmid et al. 2005). 


\section{Results}

The structure of the lampbrush chromosomes was analysed paying special attention to the comparison of the transcription-active parts and the GTG pattern on the corresponding mitotic chromosomes. The numbering of mitotic chromosome $\mathrm{G}$ bands corresponds with the numbering shown in the partial ideogram (Figure 1).

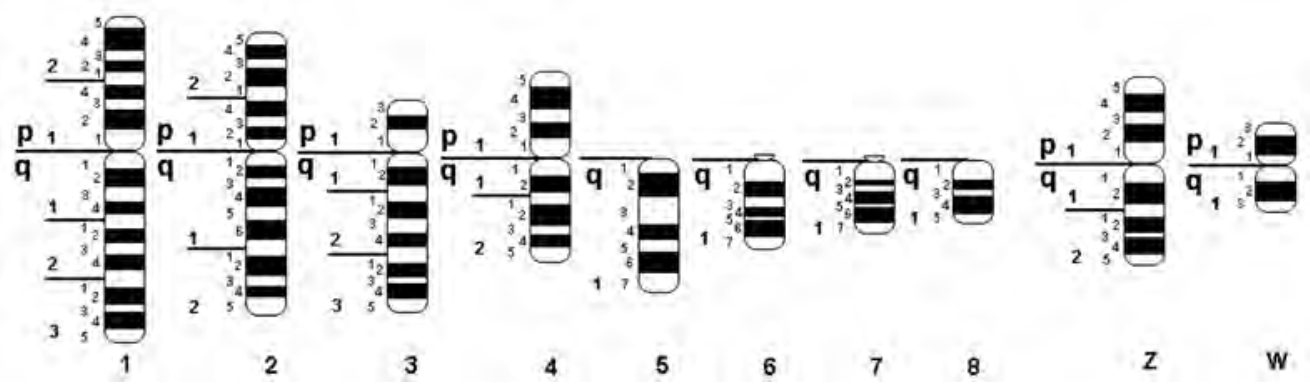

Figure 1

Partial ideogram of goose chromosomes - GTG banding

The dark blocks presented on the LBC diagram correspond to the location of the active transcription regions. The following marker structures were identified on the lampbrush chromosomes: TLs telomeric loops, TLLs telomeric lumpy loops, TBLs telomeric bow-like loops, MLs marker loops, DB double bridge, GLLs giant lumpy loops, PBs protein bodies.

The analysis results are presented in figures 2-7 consecutively for each chromosome pair. In order to ensure that the figures are clear, the ideograms of mitotic chromosomes were adjusted to the size of corresponding lampbrush bivalents.

\section{Comparison of $L B C 1$ and mitotic chromosome 1}

A wide subtelomeric block ( $A$ ) in the bivalent is analogous to band (24) situated in the distal $\mathrm{p}$-arm part of the mitotic chromosome. The narrow block (B) corresponds to band (22) whereas the two blocks (C) and (D) located side by side correspond to band (14). The wide block (E) corresponds to band (12) which is situated in the subcentromeric part of the mitotic chromosome $\mathrm{p}$ arm. The narrow block ( $\mathrm{F}$ ) in the bivalent is equivalent to the subcentromeric band (12) on the mitotic chromosome q arm. The two subsequent blocks $(\mathrm{G})$ and $(\mathrm{H})$ of similar width correspond to the wide band (24) on the mitotic chromosome. The two wide blocks (I) and $(\mathrm{J})$ correspond to the wide band (24) on the mitotic chromosome. Two very thin blocks, $(\mathrm{K})$ and $(\mathrm{L})$ can be seen in the position which, on the mitotic chromosome, is occupied by a wide light band (31) on the bivalent. The sequence of the next four blocks: $(M),(N),(0)$ and $(P)$ on the bivalent was classified as corresponding to the arrangement of the two wide bands, (32) and (34) in the distal part of the mitotic chromosome q arm. 

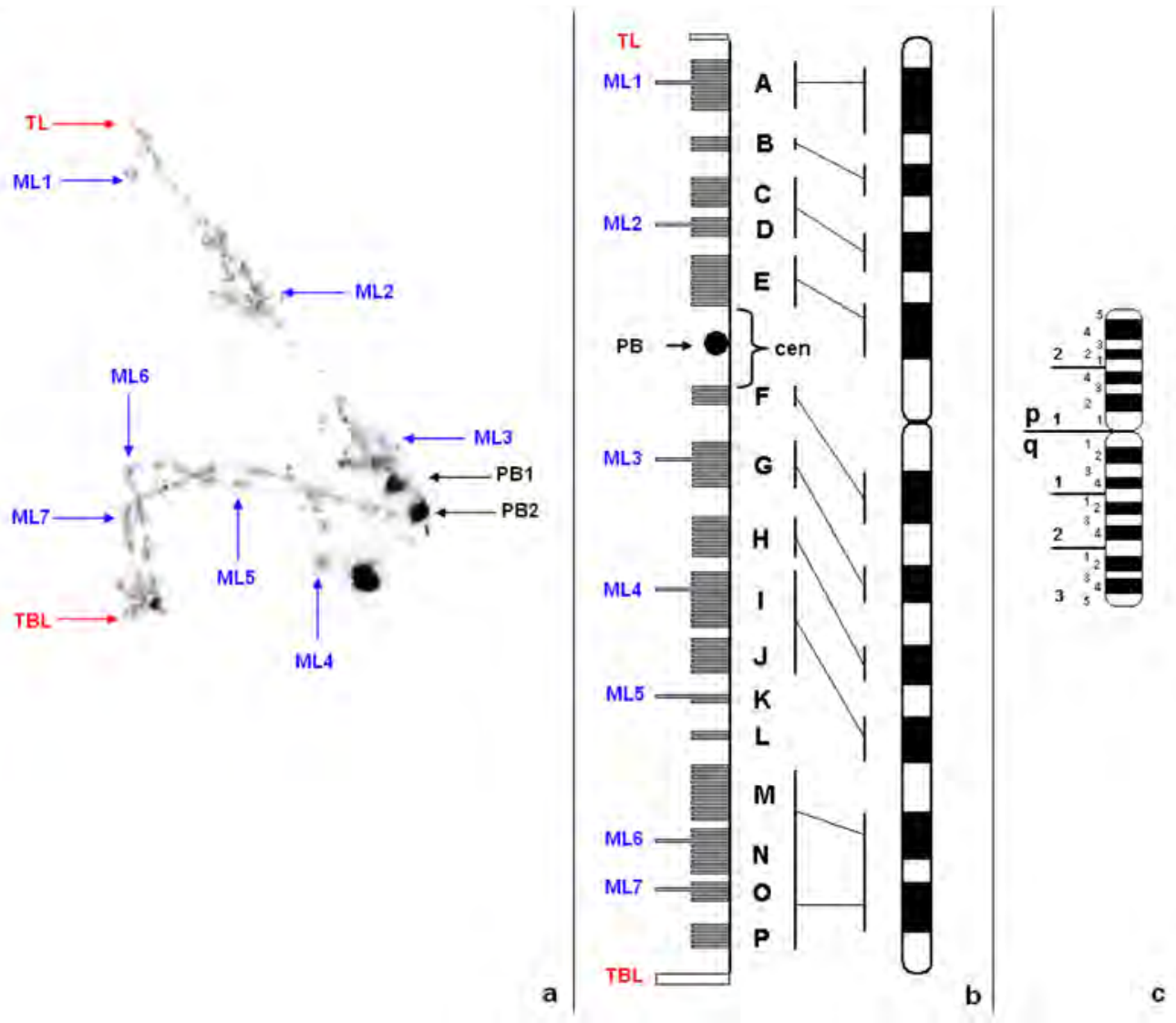

Figure 2

The first LBC with indicated marker structures (a); graphic comparison of transcription activity of the first LBC and $\mathrm{G}$ bands on the first mitotic chromosome (b); $G$ band pattern on the first mitotic chromosome (c).

\section{Comparison of $\angle B C 2$ and mitotic chromosome 2}

The two blocks (A) and (B) correspond to bands (24) and (22) located in the distal part of the mitotic chromosome arm. The wide block (C) on the bivalent corresponds to the wide band (14). The sequence of two blocks: wide (D) and narrow (E) was classified as corresponding to band (12) located in the subcentromeric part of the mitotic chromosome $\mathrm{p}$ arm. The wide block (F) corresponds to the subcentromeric band (12) on the $q$ arm of the mitotic chromosome. The arrangement of the two subsequent blocks $(\mathrm{G})$ and $(\mathrm{H})$ was classified as corresponding to the wide band (14). The next three blocks (I), (J), and (K) on the bivalent correspond to, respectively, bands (16), (22), and (24) on the mitotic chromosome. 

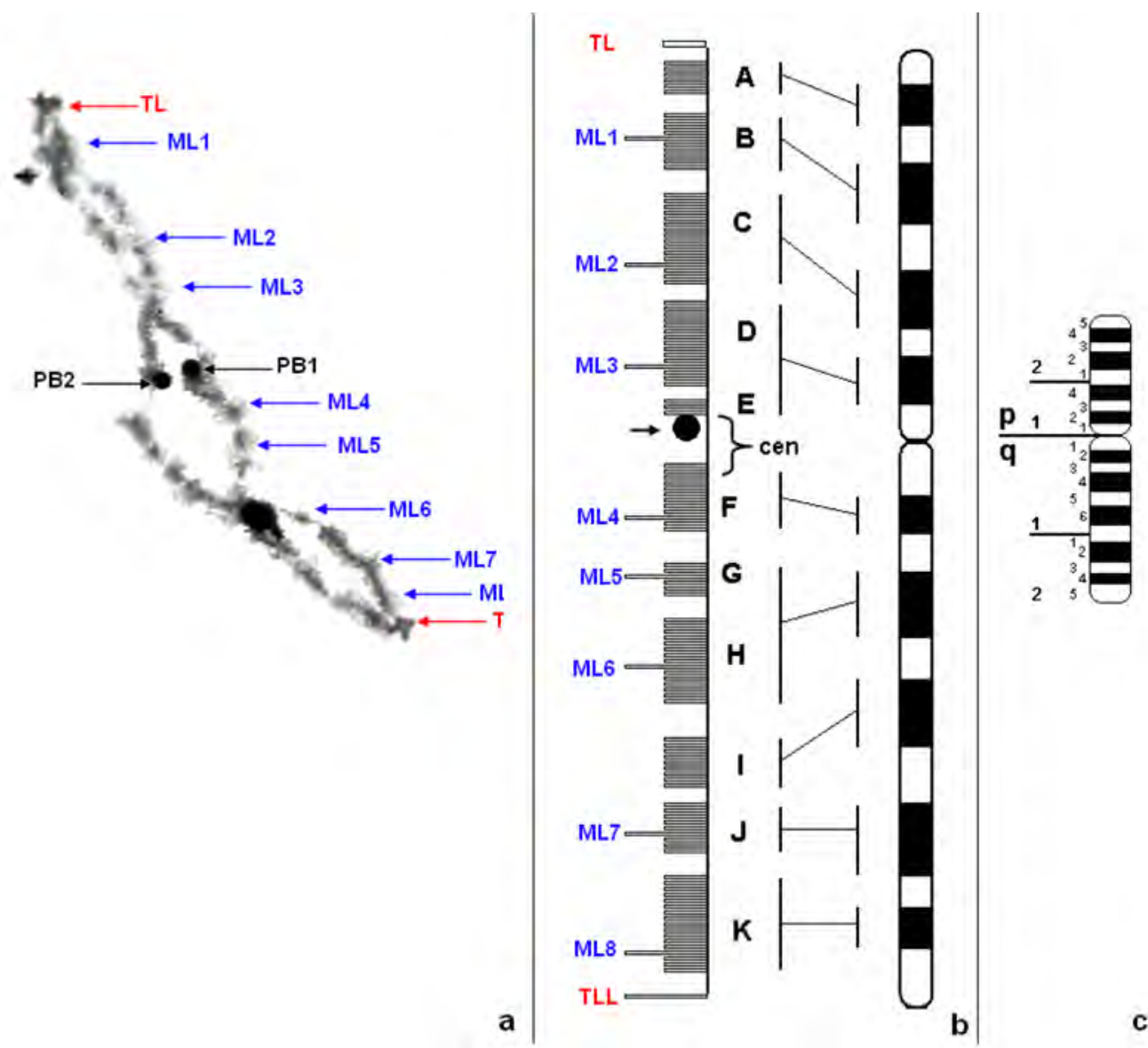

Figure 3

The second LBC with indicated marker structures (a); graphic comparison of transcription activity on the second $L B C$ and $G$ bands on the second mitotic chromosome (b); $G$ band pattern on the second mitotic chromosome (c).

\section{Comparison of $\angle B C 3$ and mitotic chromosome 3}

In the subtelomeric part of the bivalent, the wide block (A) was identified as corresponding to band (12) on the $p$ arm of the mitotic chromosome. Blocks (B), (C), and (D) corresponded to bands (12), (22), and (24) of the mitotic chromosome. A sequence of three narrow blocks: $(\mathrm{E}),(\mathrm{F})$, and $(\mathrm{G})$ was observed in the interstitial part of the bivalent at the background of a wide region without loops. The region was classified as corresponding to the wide light band (21) which constituted a boundary between the proximal and distal blocks on the mitotic chromosome. A very wide subtelomeric block $(\mathrm{H})$ on the bivalent was classified as corresponding to the sequence of bands (32) and (24) in the distal part of the mitotic chromosome q arm. 


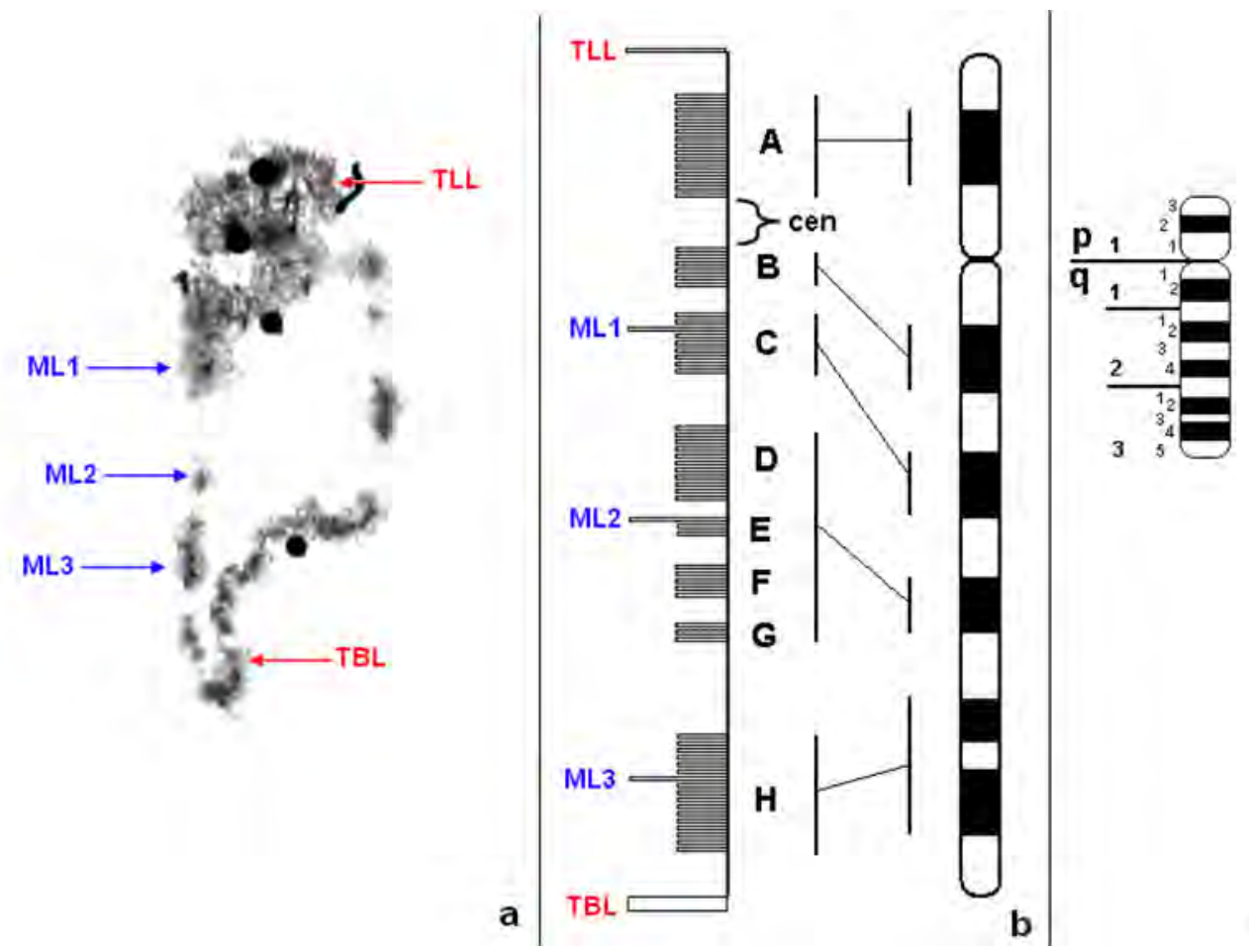

a

Figure 4

The third LBC with indicated marker structures (a); graphic comparison of transcription activity on the third LBC and $\mathrm{G}$ bands on the third mitotic chromosome (b); $G$ band pattern on the third mitotic chromosome (c).

\section{Comparison of $\angle B C 4$ and mitotic chromosome 4}

A very wide band (A) of the bivalent corresponded to the wide band (14) in the interstitial part of the $q$ arm of the mitotic chromosome. The narrow block (B) corresponded to the narrow band (12) in the subcentromeric part of the mitotic chromosome $p$ arm. Block (C) was classified as corresponding to band (12) whereas the wide block (D) was assumed to correspond to the wide band (22). The sequence of two blocks: narrow (E) and wide (F) in the distal part of the bivalent was classified as corresponding to band (24) on the mitotic chromosome.

\section{Comparison of $\angle B C 5$ and mitotic chromosome 5}

The wide block (A) of the bivalent was classified as corresponding to the wide band (12). The centrally located block (B) corresponded to band (14). Block (C) on the bivalent corresponded to the distally situated band (16) on the mitotic chromosome. 


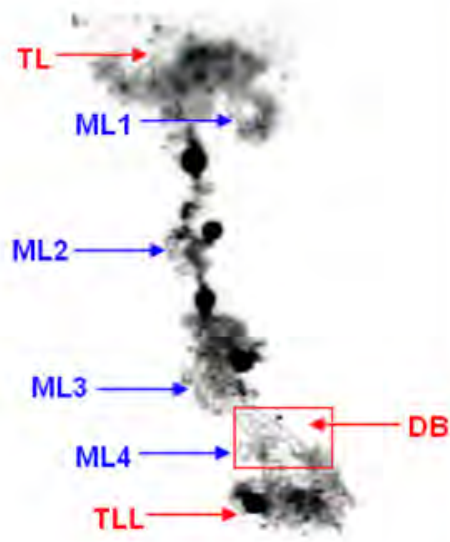

a

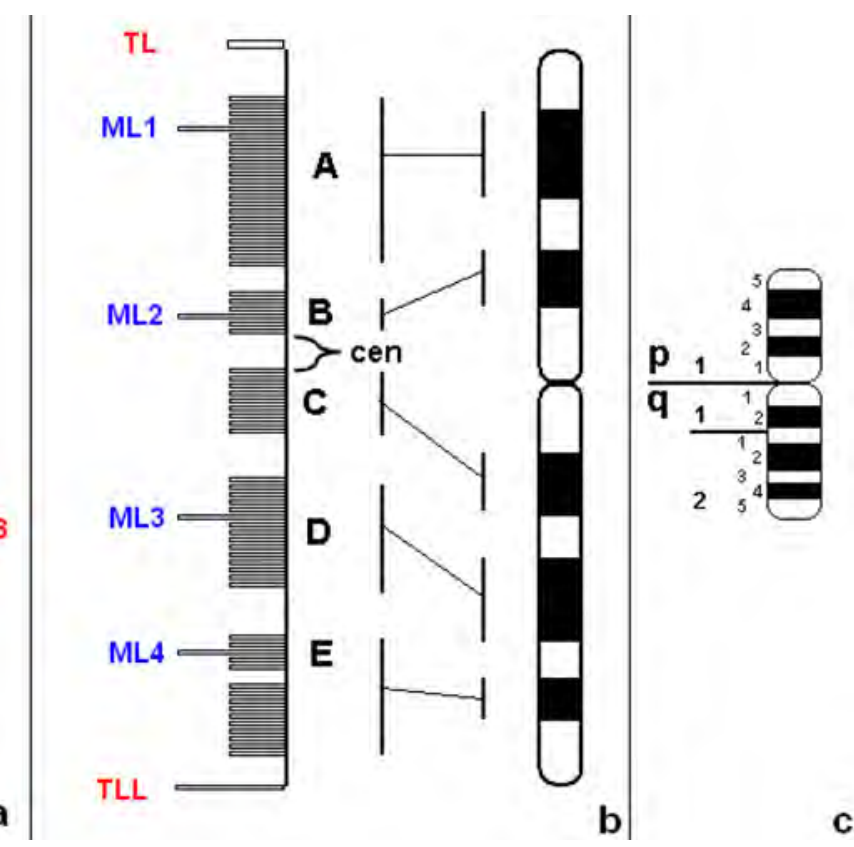

Figure 5

The fourth $\mathrm{LBC}$ with indicated marker structures (a); graphic comparison of transcription activity on the fourth $\mathrm{LBC}$ and $\mathrm{G}$ bands on the fourth mitotic chromosome (b); $G$ band pattern on the fourth mitotic chromosome (c).

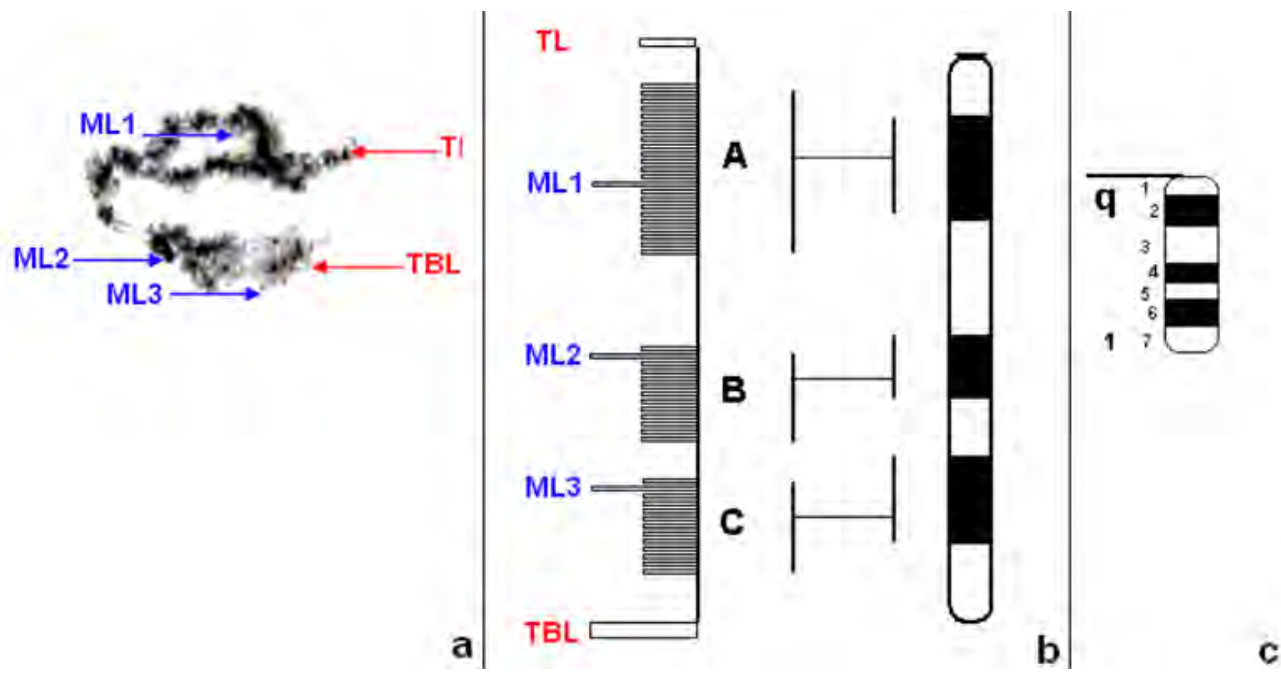

Figure 6

The fifth LBC with indicated marker structures (a); graphic comparison of transcription activity on the fifth $\mathrm{LBC}$ and $\mathrm{G}$ bands on the fifth mitotic chromosome (b); $G$ band pattern on the fifth mitotic chromosome (c). 


\section{Comparison of the lampbrush sex bivalent and mitotic chromosomes $Z$ and $W$}

The two wide blocks (A) and (B) of the bivalent corresponded to bands (14) and (12) on the mitotic chromosome. The wide block (C) corresponded to band (12) of arm q of the mitotic chromosome. Block (D) corresponded to band (22) whereas the distal block (E) corresponded to band (24) on the mitotic Z chromosome.

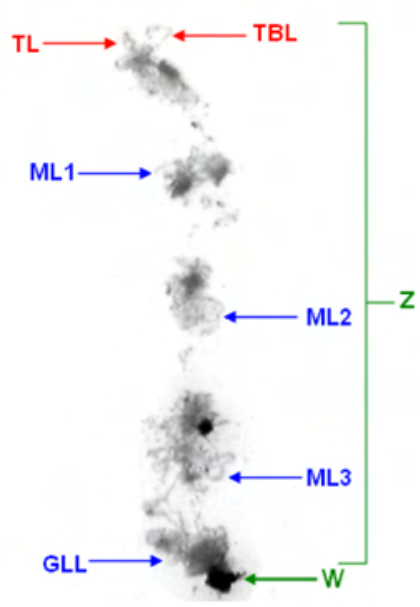

a

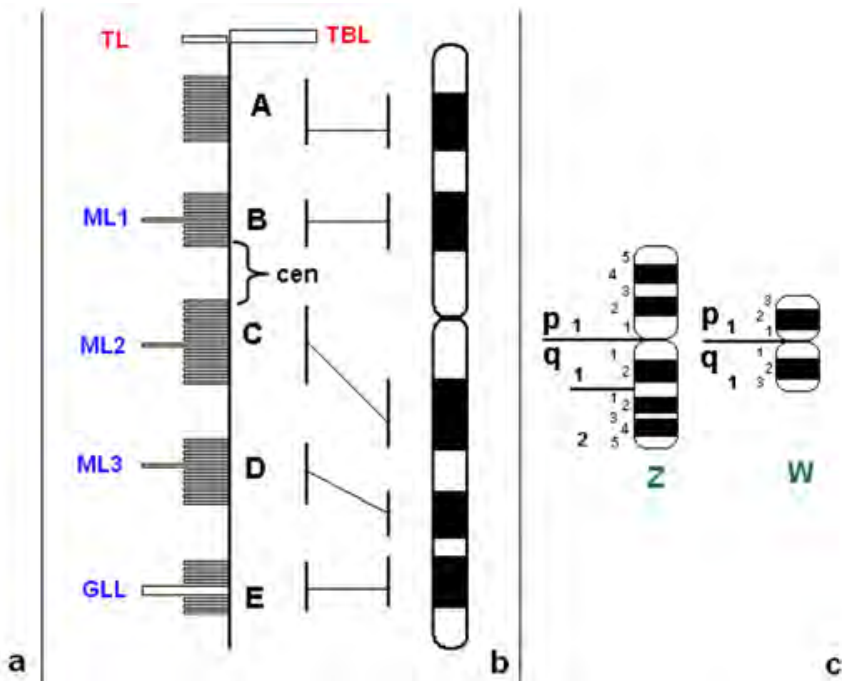

Figure 7

The sex LBCs with indicated marker structures (a); graphic comparison of transcription activity on the sex LBC and $\mathrm{G}$ bands on the sex mitotic chromosomes (b); $G$ band pattern on the sex mitotic chromosomes (c).

\section{Discussion}

The comparison of the location of regions with and without loops on the analysed lampbrush chromosomes with the GTG pattern of the corresponding mitotic chromosomes revealed that the arrangement of regions with side loops on the LBCs, which are transcription-active, corresponded to the GTG pattern on the mitotic chromosomes.

Lampbrush chromosomes constitute a new model in avian cytogenetics and have been increasingly more often used in analyses of poultry chromosomes, especially since it was found that the arrangement of transcription-active regions of LBCs is typical of the species, similarly to the banded pattern of mitotic chromosomes.

The transcription-active regions of the LBCs with well-developed side loops corresponded to the positive $\mathrm{G}$ bands. The number of the transcription-active regions determined on the lampbrush chromosomes was larger than that of the analogous $\mathrm{G}$ bands on the corresponding mitotic chromosomes. It is a result of a less condensed structure of the LBCs which makes it possible to obtain a pattern with a higher resolution. Additional bands observed on the LBCs corresponded to the location of the wide positive bands in the determined regions of the mitotic chromosomes. Consequently, the pattern of $\mathrm{G}$ bands and the pattern of dark bands on the bivalent diagram were classified as analogous. 
Studies involving a comparison of transcription active regions on LBCs and the banded pattern of mitotic chromosomes have been carried out in chickens. Gaginskaya \& Tsvetkov (1988), Rodionov et al. (1989), Galkina et al. (2001), and Rodionov et al. (2002a) used combined staining which included an application of two fluorochromes (DAPI and A3-CMA chromomycin) and found that the regions of chromomeres which were DAPI-positive stained corresponded to positive bands obtained in the $\mathrm{G}$ or $\mathrm{Q}$ banding which in turn corresponded to the regions that were rich in A-T nucleobases. The CMA stained regions corresponded to the regions which were rich in $\mathrm{G}-\mathrm{C}$ nucleobases, i.e. negative bands of the $\mathrm{G}$ and $\mathrm{Q}$ banding, and negative bands of the $\mathrm{R}$ banding. The discussed analogies are supported by the data included in the Second Report on Chicken Genes and Chromosomes (Schmid et al. 2005).

The ZW bivalent is the most difficult to identify in the whole avian LBC set. It looks like a markedly asymmetric single chromosome which predominantly has a typical lampbrush structure along its length. The $\mathrm{W}$ chromosome is almost completely heterochromatic and often assumes a characteristic bar-like shape in the distal part of the $\mathbf{Z}$ chromosome. The $Z$ and W chromosomes are connected by one chiasma in proximity to the telomere (Mizuno \& Macgregor 1998). Difficulties in identifying the sex bivalent were also indicated by Solovei et al. (1990, 1993, 1998), Mizuno \& Macgregor (1998).

An analysis of lampbrush sex bivalent structure was presented in a paper by Andraszek et al. (2009). The authors analysed the structure of lampbrush sex bivalents sampled from geese prior to and after the reproductive season. The chromosomes were found to have a different appearance before and after the egg laying. The differences stemmed from a change in the transcription activity. This confirms the connection between the transcription activity and physiological processes of the body. The changes are reflected in the morphological structure of the chromosome.

Epigenetic mechanisms active at the level of DNA methylation and histone modification change chromatin structure and control the reciprocal relation between active and inactive genes. An open heterochromatin conformation is transcription-active whereas a "closed" conformation is connected with the so-called process of transcription breakdown (Grummt \& Pikaard 2003). Lampbrush chromosomes are divided into regions of closed chromatin where sequence expression is undetectable. LBC loops are a classical example of open chromatin. Moreover, the transcription in the oocyte is a complex process in which, apart from LBCs, there are other nucleus structures engaged (Gall et al. 1999, Gall 2000, 2002, Saifitdinova 2003, Morgan 2007, Gaginskaya et al. 2009).

Studies on the structure of lampbrush chromosomes have been carried out for almost 100 years. Yet, only a concept of general LBC morphology has been accepted. The factors that initiate changes that transform condensed chromosomes into decondensed lampbrush structures are unknown. The use of LBCs in avian cytogenetics makes it possible to more broadly investigate the structure of microchromosomes, and offers a unique chance to analyse the ZW bivalent. What seems especially promising is the possibility to use lampbrush chromosomes to map bird genomes. The strategy can combine chromosome marker mapping and physical mapping of genes by means of the FISH technique, as well as involve genetic maps prepared on the basis of chiasma frequency in bivalents.

In conclusion, the comparison of the transcription activity of lampbrush chromosomes with the GTG pattern of corresponding mitotic chromosomes confirmed that the 
transcription-active areas with the side loops corresponded with the G-positive bands in the mitotic chromosomes. The results of the present work confirm the inference that the GTG differentiation staining of mitotic chromosomes in order to compare the structure of particular lampbrush chromosomes stained with CBB R250 constitutes an alternative to similar analyses carried out with the use of fluorochromes.

\section{Acknowledgements}

The authors express their deepest thanks to Alexander V. Rodionov for his patience while instructing how to obtain lampbrush chromosomes, and to Julia Loginova for her assistance and patient struggle with the natural perversity of inanimate objects.

\section{References}

Andraszek K, Smalec E (2007) Description of G bands on the chromosomes of the European domestic goose Anser anser. Arch Geflügelk 71, 272-277

Andraszek K, Smalec E, Tokarska W (2009) Identification and structure of lampbrush sex bivalents prior to and after the reproduction period of the European domestic goose Anser anser. Folia Biol (Krakow) 57, 143-148

Angelier N, Paintraud M, Lavaud A, Lechaire JP (1984) Scanning electron microscopy of amphibian lampbrush chromosomes. Chromosoma 89, 243-253

Angelier N, Bonnanfant-Jais ML, Herberts C, Lautredou N, Moreau N, N'Da E, Penrad-Mobayed M, RodriguezMartin ML, Sourrouille P (1990) Chromosomes of amphibian oocytes as a model for gene expression: significance of lampbrush loops. Int J Dev Biol 34, 69-80

Apitz M, Wagner KU, Saar W (1995) Karyotype characteristics in domestic ducks and geese. Proc. of 10th European Symposium on Waterflowl, Halle, Germany, 465-472

Austin CH, Novikova N, Guacci V, Bellini M (2009) Lampbrush chromosomes enable study of cohesin dynamics. Chromosome Res 17, 165-184

Bhatnagar MK (1968) Mitotic chromosomes of White Chinese Geese. J Hered 59, 191-195

Bitgood J, Shoffner RN (1990) Cytology and cytogenetics. In: Crowford BD (Eds) Poultry breeding and genetics. Elsevier Science Publishers, Amsterdam-Oxford-New York-Tokyo, 401-427

Callan HG, Gall JG, Berg CA (1987) The lampbrush chromosomes of Xenopus laevis: preparation, identification, and distribution of 5 S DNA sequences. Chromosoma 95, 236-250

Chelysheva LA, Solovei IV, Rodionov AV, Yakovlev AF, Gaginskaya E (1990) Lampbrush chromosomes of the chicken: the cytological map of the macrobivalents. Cytology 32, 303-316

Christidis L (1989) Kariotypic analysis in birds. In: Halnan CRE (ed.) Cytogenetics of animals. CAB International, Wallingford, 125-132

Fechheimer NS (1990) Chromosomes of Chickens. In: McFeely RA (ed.) Domestic Animal Cytogenetics. Academic Press, San Diego, Calif., 169-207

Domestic Animal Cytogenetics. Academic Press, Inc, 169-207

Gaginskaya E, Tsvetkov AG (1988) Electron microscopy research on the chromatin structure of dispersed lampbrush chromosomes in the hen. Tsitologiia 30, 142-150

Gaginskaya E, Kulikova T, Krasikova A (2009) Avian Lampbrush Chromosomes: a Powerful Tool for Exploration of Genome Expression. Cytogenet Genome Res 124, 251-267

Gall JG (1983) Transcription of repetetive sequences on Xenopus lampbrush chromosomes. Proc Natl Acad Sci USA 80, 3364-3367

Gall JG (2000) Cajal bodies: the first 100 years. Annu Rev Cell Dev 16, 273-300

Gall JG, Bellini M, Zheng'an W, Murphy C (1999) Assembly of the nuclear transcription and processing machinery: Cajal bodies (coiled bodies) and transcriptosomes. Mol Biol Cell 10, 4385-4402 
Galkina S, Lukina N, Vasilieva E, Andreozzi L, Saccone S, Bernardi G, et al. (2001) Analysis of correspondence between Q-banding pattern of lampbrush chromosomes by FISH and fluorochrome staining. Proceedings of 3d European Cytogenetic Conference, Paris. Ann Genet 44 (Suppl. 1), 38

Galkina S, Deryusheva S, Fillon V, Vignal A, Crooijmans R, Groenen M, Rodionov A, Gaginskaya E (2006) FISH on avian lampbrush chromosomes produces higher resolution gene mapping. Genetica 128, 241-251

Grummt I, Pikaard CS (2003) Epigenetic silencing of RNA polymerase I transcription. Nat Rev Mol Cell Biol 4, 641-649

Guttenbach M, Nanda I, Feichtinger W, Masabanda JS, Griffin DK, Schmid M (2003) Comparative chromosome painting of chicken autosomal paints 1-9 in nine different bird species. Cytogenet Genome Res 103,173-184

Hidas A (1993) Cytogenetic studies on a species hybrid goose breed. 8th North American Colloqium on Domestic Animal Cytogenetic and Gene Mapping, Guelph, Canada, 153-155

Hutchison N (1987) Lampbrush chromosomes of the chicken, Gallus domesticus. J Cell Sci 105, 493-500

Itoh M, Ikeuchi T, Shimba H, Mori M, Sasaki M, Makino S (1969) A comparative karyotype study in fourteen species of birds. Japan J Genet 44, 163-170

Jaszczak K, Rabsztyn A, Jaszczak J, Kapkowska E (1999) A kariotype survey of early goose embryos. Anim Sci Pap Rep 17, 67-72

Jaszczak K, Zawadzka M, Jaszczak J, Rabsztyn A (2002) Karyotype vs DNA fingerprinting in geese. Anim Sci Pap Rep 20, 103-109

Krasikova A, Kulikova T, Saifitdinova A, Derjusheva S, Gaginskaya E (2004) Centromeric protein bodies on avian lampbrush chromosomes contain a protein detectable with an antibody against DNA topoisomerase II. Chromosoma 113, 316-323

Kropotova EV, Gaginskaya E (1984) Lampbrush chromosomes from Japanese quail oocytes. Tsitologia 26, 1008-1014

Ladjali-Mohammedi K, Botgood JJ, Tixier-Boichard M, Ponce De Leon FA (1999) International System for Standardized Avian Karyotypes (ISSAK): Standardized Banded Karyotypes of the Domestic Fowl (Gallus domesticus). Cytogenet Cell Genet 86, 271-276

Macgregor HC (1984) The lampbrush chromosomes of animal oocytes, In: Risley M (ed.) Chromosome Structure and Function, Van Rostrand and Reinhold Publishing Corp, New York, 152-186

Macgregor HC (1987) Lampbrush chromosomes. J Cell Sci 88, 7-9

Macgregor HC, Varley J (1988) Working with Animal Chromosomes. John Wiley \& Sons, London, New York, Brisbane, Toronto, Singapore

Mayr B, Lambrou M, Kalat M, Schleger W, Bigelbach A (1990) Characterization of heterochromatin by seqential counterstain - enhanced fluorescence in three domestic bird species. Hereditas 8, 468-475

Mizuno S, Macgregor HC (1998) The ZW lampbrush chromosomes of birds: unique opportunity to look at the molecular of sex chromosomes. Cytogenet Cell Genet 80, 149-157

Morgan GT (2002) Lampbrush chromosomes and associated bodies: new insights into principles of nuclear structure and function. Chromosome Res 10, 177-200

Morgan GT (2007) Localized co-transcriptional recruitment of the multifunctional RNA-binding protein CELF1 by lampbrush chromosome transcription units. Chromosome Res 15, 985-1000

Rabsztyn A, Jaszczak K, Jaszczak J, Kapkowska E (1998) Inheritance of two morphological forms of chromosome 4 in Zatorska geese. Allatenyesztes es Takarmanyozisenetics of Domestic Animals 48, 72-74

Rodionov AV (1996) Micro versus macro: a review of structure and functions of avian micro- and macrochromosomes. Genetika 32, 597-608

Rodionov AV, Chechik MS (2002) Lampbrush chromosomes in the Japanese quail (Coturnix coturnix japonica): cytological maps of macro chromosomes and meiotic crossover frequency in females. Genetika 38, 1246-1251

Rodionov AV, Chelysheva LA, Gaginskaya E (1989) Heterochromatin regions chromosomes of the Japanese quail in mitosis and at the lampbrush stage. Tistologiia 31, 867-873

Rodionov AV, Galkina SA, Lukina NA, Pichugin A, Vasiliev AE, Zakharova K, et al. (2002a) Comparative mapping of chicken lampbrush and mitotic chromosomes by FISH and DAPI/CMA-staining. Chromosome Res 10 (Suppl 1), 5 
Rodionov AV, Galkina SA, Lukina NA, Solovei I, Saccone S (2002b) Crossing over in chicken oogenesis: cytological and chiasma-based genetic maps of the chicken lampbrush chromosome 1.J Hered 93, 125-129

Saifitdinova A, Derjusheva S, Krasikova A, Gaginskaya E (2003) Lampbrush chromosomes of the chaffinch (Fringilla coelebs L.). Chromosome Res 11, 99-113

Seabright M (1971) A rapid banding technique for human chromosomes. Lancet 2, 971-972

Schmid M, Nanda I, Guttenbach M, Steinlein C, Hoehn H, Schartl M, Haaf T, Weigend S, Fries R, Buerstedde JM, Wimmers K, Burt DW, Smith J, A'Hara S, Law A, Griffin DK, Bumstead N, Kaufman J, Thomson PA, Burke T, Groenen MAM, Crooijmans RPMA, Vignal A, Fillon V, Morisson M, Pitel F, Tixier-Boichard M, LadjaliMohammedi K, Hillel J, Maki-Tanila A, Cheng HH, Delany ME, Burnside J, Mizuno S (2000) First Report on Chicken Genes and Chromosomes 2000. Cytogenet Cell Genet 90, 169-218

Schmid M, Nanda I, Hoehn H, Schartl M, Haaf T, Buerstedde JM, Arakawa H, Caldwell RB, Weigend S, Burt DW, Smith J, Griffin DK, Masabanda JS, Groenen MAM, Crooijmans RPMA, Vignal A, Fillon V, Morisson M, Pitel F, Vignoles M, Garrigues A, Gellin J, Rodionov AV, Galkina SA, Lukina NA, Ben-Ari G, Blum S, Hillel J, Twito T, Lavi U, David L, Feldman MW, Delany ME, Conley CA, Fowler VM, Hedges SB, Godbout R, Katyal S, Smith C, Hudson Q, Sinclair A, Mizuno S (2005) Second Report on Chicken Genes and Chromosomes 2005. Cytogenet Genome Res 109, 415-479

Shoffner RN, Wang N, Lee F, King R, Otis JS (1979) Chromosome homology between the Ross's and the Emperor goose. J Hered 70, 395-400

Silversides FG, Crawford RD, Wang HC (1988) The cytogenetics of domestic geese. J Hered 79, 6-8

Solovei IV, Khutinaeva MA, Chelysheva LA, Rodionov AV, Gaginskaya E (1990) Lampbrush sex bivalent of birds: identification and structure. Cytology 32, 817-825

Solovei IV, Gaginskaya E, Allen T, Macgregor HC (1992) A novel structure associated with lampbrush chromosomes in the chicken, Gallus domesticus. J Cell Sci 101, 759-772

Solovei IV, Gaginskaya E, Hutchison N, Macgregor HC (1993) Avian sex chromosomes in the lampbrush form: the ZW lampbrush bivalents from six species of bird. Chromosome Res 1, 153-160

Solovei IV, Gaginskya ER, Macgregor HC (1994) The arrangement and transcription of telomere DNA seqences at the ends of lampbrush chromosomes of birds. Chromosome Res 2, 460-470

Solovei IV, Macgregor HC, Gaginskaya E (1995) Single stranded nucleic acid binding structures on chicken lampbrush chromosomes. J Cell Sci 108, 1391-1396

Solovei IV, Joffe BI, Gaginskaya ER, Macgregor HC (1996) Transcription of lampbrush chromosomes of a centromerically localized highly repeated DNA in pigeon (Columba) relates to sequence arrangement. Chromosome Res 4, 588-603

Solovei IV, Joffe BI, Hori T, Thomson P, Mizuno S, Macgregor HC (1998) Unordered arrangement of chromosomes in the nuclei of chicken spermatozoa. Chromosoma 107, 184-188

Vlad M, Macgregor HC (1975) Chromomere number and its genetic significance in lampbrush chromosomes. Chromosoma 50, 327-347

Wójcik E, Smalec E (2007) Description of the Anser anser goose kariotype. Folia Biol (Krakow) 55, 35-40

Wójcik E, Smalec E (2008): Description of the Anser cygnoides goose karyotype. Folia Biol (Krakow) 56, 37-42

Received 23 June 2010, accepted 21 October 2010.

Corresponding author:

Katarzyna Andraszek

email: andrasz@ap.siedlce.pl

Department of Animal Genetics and Horse Breeding, Institute of Bioengineering and Animal Breeding, University of Life Sciences and Humanities, Prusa 14, 08-110 Siedlce, Poland 